\title{
MATERIAL PARTICULADO EM MOTORES OTTO DE INJEÇÃO DIRETA - UMA REVISÃO ATUALIZADA DA LITERATURA
}

\author{
Igor Faust Ostapiuk $^{1}$, Luiz Carlos Daemme ${ }^{2}$ e Renato Penteado ${ }^{2}$ \\ ${ }^{1}$ Prodetec \\ ${ }^{2}$ Institutos Lactec
}

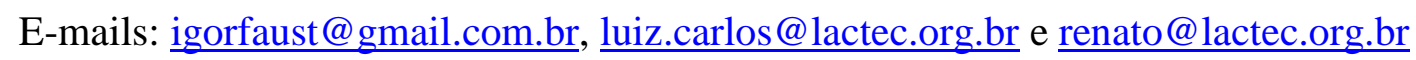

\section{RESUMO}

Para enfrentar os desafios impostos pela legislação ambiental e em busca de uma eficiência energética a indústria automotiva vem desenvolvendo e aplicando a tecnologia de injeção direta em motores do ciclo Otto. Apesar das conhecidas vantagens, tal tecnologia apresenta fatores negativos, com destaque à formação de material particulado (MP).

A formação de MP em motores Diesel é um fenômeno já conhecido, contudo nos motores Otto continua sendo um tema a ser mais bem estudado, principalmente sobre a concentração de MP de diâmetro médio nominal menor que 2,5 micrometros (PM2,5) nos gases de escape.

Pela importância do tema, nas recentes revisões da legislação europeia foram impostos limites para emissão de MP em motores de injeção direta.

O objetivo do presente artigo foi apresentar uma revisão atualizada a respeito da emissão de MP em motores Otto de injeção direta, enfocando as mais importantes publicações sobre o tema, o estado da arte e as legislações em vigor.

\section{INTRODUÇÃO}

O desenvolvimento e principalmente a aplicação de novas tecnologias no mercado de consumidores finais, passa por uma etapa de equilíbrio entre dos custos atrelados e os benefícios oriundos da tecnologia. Nos últimos anos, a eficiência energética tem sido um dos principais veios de pesquisa e desenvolvimento de toda a comunidade científica. Na indústria automotiva, com a evolução dos programas de controle de emissões de poluentes e a forte demanda para otimização do consumo de combustível dos veículos automotores, novas tecnologias foram introduzidas no mercado. A Figura 1 apresenta o panorama das emissões de veículos automotores na Europa, ao longo dos anos. A partir de 1995, ocorreu uma inversão nas emissões de $\mathrm{CO}_{2}$ apresentando uma tendência contrária aos outros poluentes medidos, ou seja, uma tendência de crescimento. Desta forma, alinhados a programas globais de redução dos gases do efeito estufa, os motores de combustão interna necessitam evoluir para contribuir de forma positiva na redução das emissões de $\mathrm{CO}_{2}$. Assim sendo, buscando aliar a potência específica dos motores a gasolina com a eficiência dos motores Diesel, a injeção direta de combustível vem sendo desenvolvida e aplicada em motores Otto. 


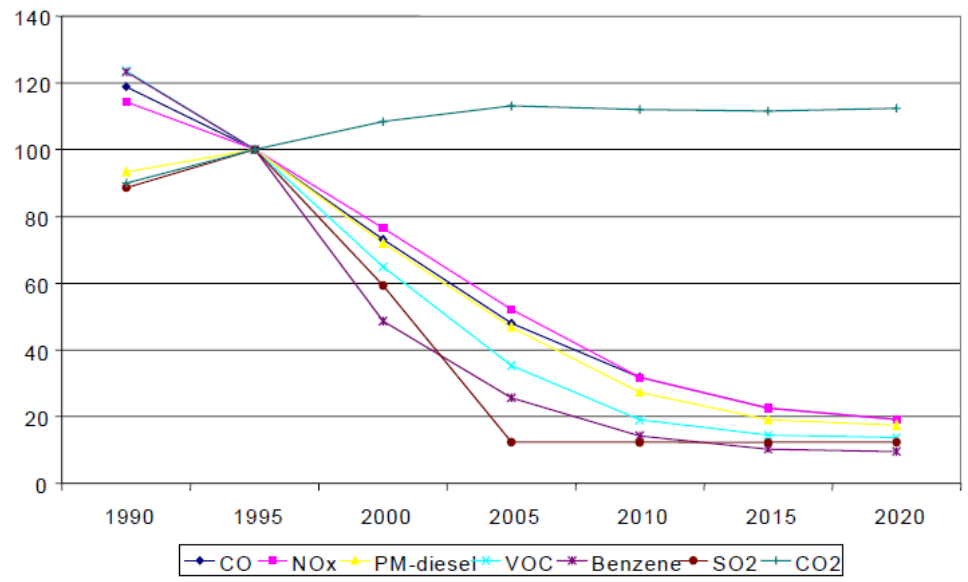

Figura 1 - Evolução das emissões de poluentes oriundas de veículos na Europa [1].

\section{A INJEÇÃO DIRETA}

De forma similar aos motores Diesel, nos motores do ciclo Otto com injeção direta o combustível é injetado diretamente na câmara de combustão e a potência específica é controlada através da quantidade de combustível injetada. A Figura 2 apresenta o esquemático dos motores de injeção direta e de pré mistura.
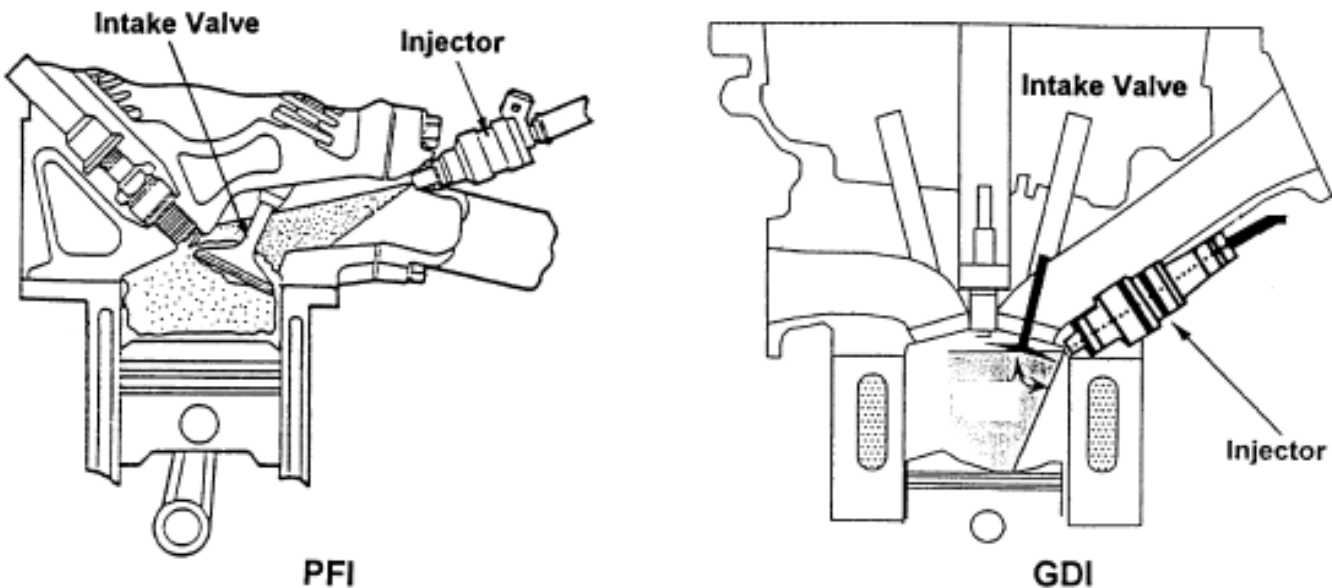

Figura 2 - Esquemático dos motores de pré mistura e de injeção direta [2].

A principal diferença entre os conceitos está relacionada à estratégia de preparação da mistura ar/combustível. Nos motores de pré mistura, a injeção de combustível ocorre no coletor de admissão e as características da mistura são função da geometria do sistema de admissão e escoamento do ar admitido. Nos motores de injeção direta, o combustível é injetado no interior da câmara de combustão. A Figura 3 apresenta as três classificações do processo de combustão da tecnologia de injeção direta. 


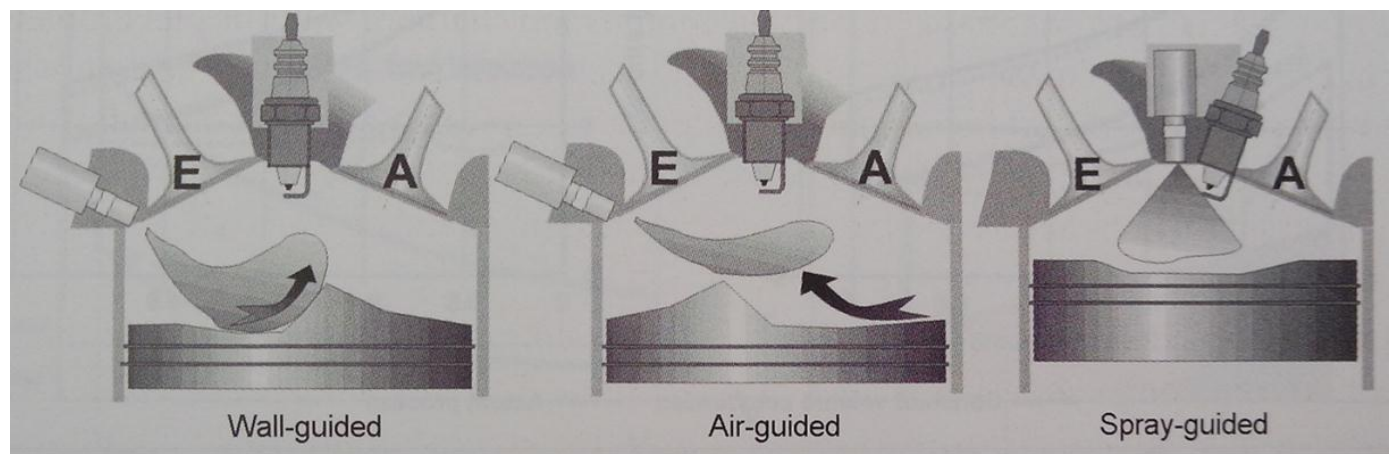

(a) (b) (c)

Figura 3 - Classificação do processo de combustão dos motores de injeção direta [3].

No processo de combustão guiado pela parede, Figura 3-(a), ocorre uma interação entre o combustível injetado e as paredes da câmara de combustão. Neste caso, as características da mistura estão diretamente ligadas à geometria da câmara, uma vez que o combustível é injetado na cabeça do pistão e sua geometria promove o deslocamente da mistura até a vela de ignição. As principais limitações deste conceito são as altas emissões de hidrocarbonetos não queimados, principalmente devido ao acúmulo de combustível nas paredes da câmara, bem como o controle da injeção e escoamento do ar admitido em condições transientes de operação, uma vez que o perfil de escoamento do ar está diretamente ligado às características da mistura na região próxima à vela de ignição.

Na combustão guiada pelo ar, Figura 3-(b), as características da mistura também são função da geometria da câmara e do perfil de escoamento, entretanto, o combustível é injetado diretamente no ar com perfil de escoamento turbulento criado pela cabeça do pistão. Desta forma, teoricamente não ocorre acúmulo de combustível nas paredes da câmara, reduzindo assim as emissões de hidrocarbonetos não queimados e material particulado. Contudo, as perdas em função do perfil de escoamento criado no interior da câmara geram uma menor efficiência volumétrica do ciclo e consequentemente seu desempenho é comprometido.

O terceiro conceito de processo de combustão é o denominado guiado por spray, Figura 3-(c). Caracterizado pela proximidade do injetor com a vela de ignição, neste processo a mistura ar/combustível ocorre em função de interações aerodinâmicas. Sendo diretamente dependente do perfil do spray de combustível injetado, tal conceito apresenta relevantes gradientes de estratificação, ou seja, há regiões no interior do perfil do spray ricas em combustível e regiões na periferia do perfil pobres em combustível. Tal característica heterogênea da mistura ar/combustível acarreta instabilidades no processo de combustão, logo, apresenta impactos nas emissões de poluentes. As principais limitações deste conceito estão relacionadas às altas cargas térmicas na vela de ignição, processo de manufatura dos injetores e características da mistura ar/combustível em condição transiente de operação.

Com a injeção de combustível sob alta pressão na câmara de combustão, ocorre a vaporização do combustível, logo, a temperatura na câmara é reduzida permitindo assim maiores taxas de compressão e condição ultra-pobre de funcionamento. Como resultado final, é possível obter menores valores de consumo específico de combustível. Alkidas [4] concluiu que motores de injeção direta atingem até $15 \%$ de redução de consumo, quando comparados com motores de pré-mistura. Além das condições da combustão, as menores perdas de bombeamento, devido principalmente à ausência da válvula borboleta no sistema de admissão, podem representar até 
$10 \%$ de redução de consumo. Em condições otimizadas, motores de injeção direta podem atingir até $26 \%$ de redução de consumo.

Outro notório benefício está relacionado à emissão de hidrocarbonetos não queimados na partida a frio. Zhao [2] descreve que, devido às condições da mistura na região próxima a vela de ignição, os motores de injeção direta não requerem grandes quantidades de combustível e, consequemente, ciclos para atingir uma condição estável de combustão. A Figura 4 apresenta um gráfico comparativo da quantidade de combustível necessária para início de operação em diferentes temperaturas. Entretanto, para aplicação em larga escala da tecnologia, desafios e dificuldades foram enfrentados, dentre as quais, o controle estratificado da combustão em diferentes níveis de carga e as emissões de material particulado e óxidos de nitrogênio $\left(\mathrm{NO}_{\mathrm{x}}\right)$, que ganharam destaque na comunidade internacional.

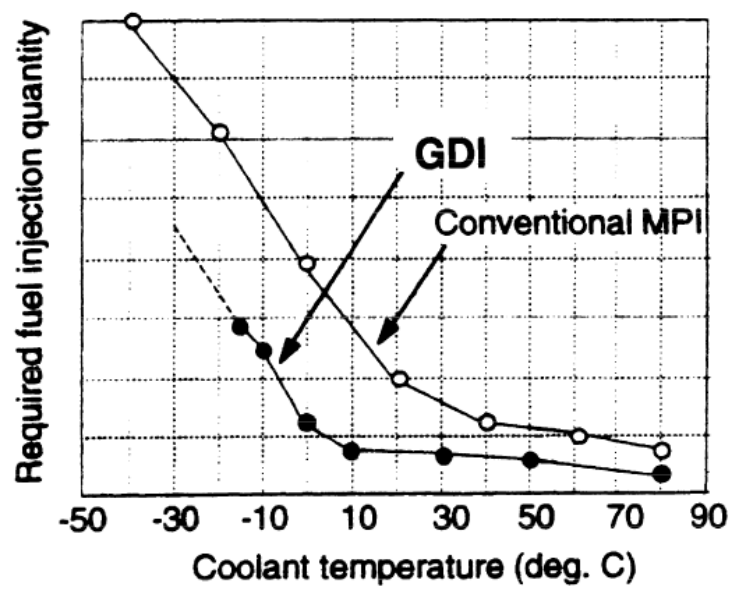

Figura 4 - Comparativo da quantidade de combustível necessária para início de operação [2].

Diferente dos sistemas de pré-mistura, neste conceito as características do sistema de injeção são de suma importância na operação, uma vez que o processo de combustão é dependente do perfil do spray de combustível injetado na câmara, e não da mistura ar-combustível.

\section{HISTÓRICO DA TECNOLOGIA}

O desenvolvimento da tecnologia de injeção direta de combustível é tão antigo quanto o conceito de pré-mistura. Os primeiros testes são datados em 1898, quando Haselwander desenvolveu um motor de combustão externa alimentado com derivado de petróleo, onde o combustível era injetado antes que o pistão atingisse o ponto motor superior. Entretando, devido as limitações tecnológicas da época, os resultados inicias não foram satisfatórios e o desenvolvimento foi suspenso.

Com o início da primeira guerra mundial, o segmento de aviação alavancou o desenvolvimento de novas tecnologias aplicadas a motores de combustão interna. Numa primeira abordagem, os motores utilizavam Diesel como combustível, contudo, devido a imposições governamentais e problemas com os sistemas de alimentação de Diesel, a gasolina e benzeno assumiram um papel importante na matriz de combustíveis utilizados naquele período. Em 1916, sob gerenciamento de Otto Marder, o motor Junkers' Fo2 foi desenvolvido. Inicialmente concebido com taxa de compressão de 10:1, o motor apresentou problemas de sobre-aquecimento das velas, desencadeando assim o início do desenvolvimento de velas resfriadas a água por parte da Bosch. Outra medida tomada visando reduzir a temperatura da câmara de combustão, foi diminuir a taxa de compressão para 6:1, mas os 
problemas de sobre-aquecimento não foram resolvidos até 1918, data em que as atividades de desenvolvimento foram interrompidas devido ao final da primeira guerra mundial. Todavia, um relatório emitido por Otto Marder cita que a Junkers atingiu um bom controle da injeção de gasolina, com reduzido risco de incêndio e que foram também apurados os ajustes da mistura ar combustível, principalmente em altas altitudes de vôo [3].

No início dos anos 30, com incentivo do Ministério dos Transportes alemão e baseado no desenvolvimento realizado pela Junkers, Kurt Schnauffer apresentou resultados de melhor desempenho dos motores BMW IV e Siemens Sh 13, equipados com arquitetura Diesel de injeção, quando operados com injeção direta, se comparados com sistema de alimentação por carburador. Em 1934, utilizando um motor BMW aeronáutico, K. Schnauffer apresentou um aumento de $17 \%$ da potência e redução de $3 \%$ do consumo de combustível, ganhos estes oriundos da injeção direta de combustível. Desta forma, o governo alemão fomentou o desenvolvimento da tecnologia e em 1937 os primeiros motores aeronáuticos, equipados com injeção direta, foram produzidos em larga escala [5].

Os bons resultados da tecnologia no ramo aeronáutico, fizeram com que ainda nos anos 30 testes fossem realizados na indústria automotiva. Visando extrair ao máximo as vantagens dos motores Diesel e Otto, Hesselman criou um motor de injeção direta, onde o combustível era injetado na fase de compressão e a mistura ocorria devido ao uso de válvulas que geravam turbulência no escoamento do ar na câmara de combustão. Este sistema apresentou bons resultados de potência e consumo, mas, principalmente, a habilidade de ser abastecido com diferentes combustíveis. Ainda na década de 1930, a Daimler-Benz e outras companhias iniciaram pesquisas visando o desenvolvimento de motores mono-cilíndricos para carros de corrida, mas com o início da segunda guerra mundial tais atividades foram suspensas. Após o término da guerra e com mais apurados dados da indústria aeronáutica, em 1949 a Bosch, em parceria com outras empresas, retomou as pesquisas com motores de injeção direta, entretanto o desafio imposto fora subestimado. Por se tratar principalmente de motores de dois tempos, via de regra as dificuldades estavam relacionadas às velocidades dos motores e ruídos gerados nos sistema de injeção.

No decorrer dos anos, otimizações no sistema foram desenvolvidas e em 1952 a DaimlerBenz iniciou o desenvolvimento do motor 3.0 L de quatro tempos com injeção direta, que em 1954 entrou em produção, equipando o modelo Daimler-Benz 300SL. A Figura 5 apresenta as curvas de potência e consumo de combustível do motor Daimler-Benz de quatro tempos quando equipado com carburador e sistema de injeção direta. Além da redução no consumo de combustível, o valor de pico de potência é aproximadamente $10 \%$ maior quando utiliza injeção direta, se comparado com carburador. Equipado com sistema de injeção Bosch e pressão de injeção de 45bar, a mistura ar/combustível é controlada através de uma válvula borboleta e para operações em altitude, um medidor barométrico integrado no sistema de controle da bomba de injeção atua nas condições da mistura ar/combustível. 


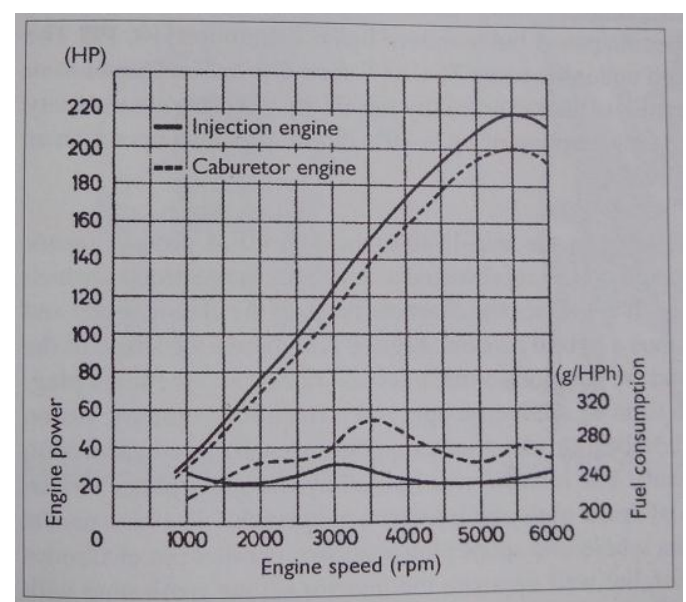

Figura 5 - Comparação de potência e consumo de combustível do motor Daimler-Benz equipado com carburador e injeção direta [3].

Na década de 1950, a injeção direta foi aplicada com sucesso em carros de corrida pela Daimler-Benz e Borgward, contudo, nos anos 60 e 70 o desenvolvimento da tecnologia entrou em recessão pela redução no preço dos combustíveis e consideráveis avanços no desenvolvimento de motores de pré-mistura. Desta forma, o desenvolvimento se resumiu apenas em institutos de pesquisa da indústria automotiva e petroquímica.

O primeiro conceito de injeção direta estratificada foi apresentado em 1949 pela Texaco. O objetivo principal do processo TCP (Texaco Combustion Process) era reduzir o consumo de combustível sem alterar o desempenho do motor, e em 1986 apresentou redução de até 30\% no consumo, quando comparado com o motor de referência. Entre as décadas de 60 e 80, o processo MAN FM também foi desenvolvido. Neste caso, o combustível era injetado na forma de spray no rebaixo da cabeça do pistão e, devido às altas temperaturas da câmara e características de design do pistão, o combustível era reevaporado atingindo as condições necessárias para combustão na região próxima à vela de ignição.

Outras companhias também contribuíram no desenvolvimento da tecnologia e com destaque, nos meados da década de 50 para a Ford que apresentou o processo FCP (Ford Combustion Process). Utilizando um injetor de grande dispersão, aproximadamente $100^{\circ}$, localizado no eixo da linha de centro do pistão e sem aparatos para controle do ar admitido, o sistema foi caracterizado pelo consumo de combustível otimizado, baixa emissão de poluentes e altos valores de potência específica. Em 1976, a Mitsubishi apresentou o processo MCP (Mitsubishi Combustion Process). Neste conceito, o combustível é injetado no contra-fluxo do ar admitido, promovendo assim uma rápida evaporação do combustível e boas características da mistura na região da centelha. A principal característica deste sistema está relacionada ao perfil do spray de combustível, que varia conforme a carga do motor [2,3].

O desenvolvimento e a aplicação em larga escala dos processos supracitados foram limitados pela tecnologia disponível na época. Contando com sistemas mecânicos de injeção e limitações no controle da injeção, formação da mistura e combustão, os resultados de resposta dos motores em condições transientes não foram satisfatórios. Logo, o desenvolvimento da tecnologia entrou novamente em recessão e, no final da década de 80, publicações científicas retomaram o potencial do sistema de injeção direta. Nesta etapa, o principal foco era o desenvolvimento de motores de dois tempos, que devido as altas emissões de poluentes, não 
foram aplicados em veículos automotores, se limitando a aplicações fora de estrada e motocicletas.

No ano de 1995, no International Motor Show (IAA) a Mitsubishi apresentou o primeiro conceito da nova geração de motores de injeção direta. A Figura 6 apresenta o princípio de funcionamento do denominado motor GDI (Gasoline Direct Injection). Neste conceito, o combustível é injetado num rebaixo da cabeça do pistão, que devido sua geometria característica cria a mistura ar/combustível necessária para combustão, o denominado conceito guiado pela parede. Inicialmente este motor foi aplicado no Mitsubishi Galant, que com um conversor catalítico seletivo atingiu patamares aproximados de $60 \%$ de redução de $\mathrm{NO}_{\mathrm{x}}$.

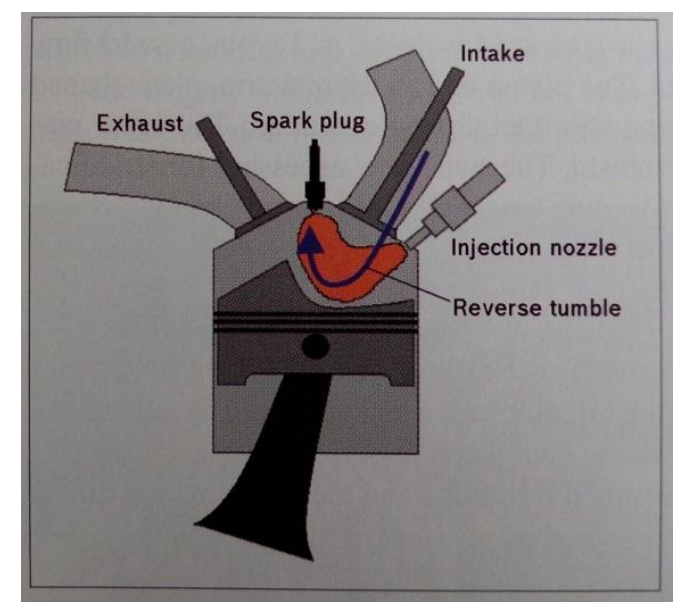

Figura 6 - Princípio do motor Mitsubishi GDI [3].

Na Figura 7 são apresentadas as curvas de desempenho do motor Mitsubishi quando equipado com sistema de injeção direta e pré-mistura. É possível notar que o motor com injeção direta e taxa de compressão de 12:1, apresentou um acréscimo de $10 \%$ no torque em altas rotações. A eficiência volumétrica do motor Mitsubishi é outro ponto de destaque, uma vez que quando comparado com um motor de pré-mistura foi $5 \%$ maior em todas as condições de operação do motor.

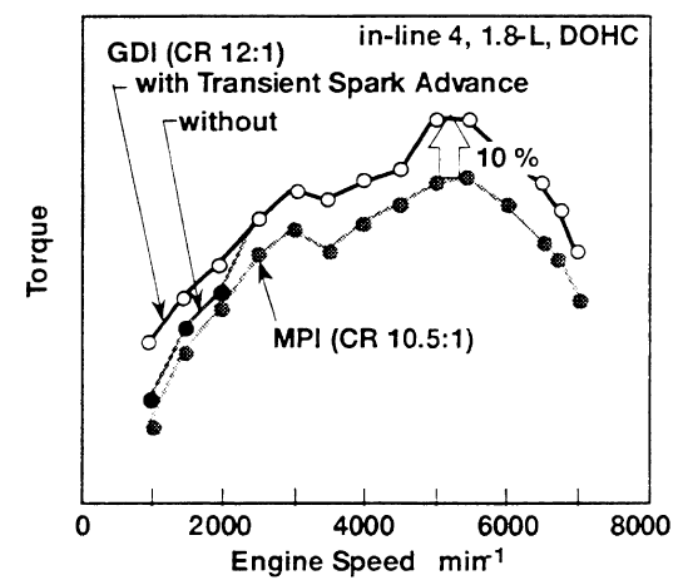

Figura 7 - Performance do motor Mitsubishi GDI [2].

Dando sequência no desenvolvimento, em 1996 a Toyota lançou o motor D4. Sua principal característica era a presença de uma válvula de controle de fluxo no sistema de admissão, permitindo assim diferentes modos de operação no motor. Em regimes de baixa rotações e carga, a válvula restringe parcialmente a vazão de ar admitida, gerando assim maior 
velocidade de escoamento do ar. Esta condição é necessária para gerar os vórtices que guiam a mistura ar/combustível, permitindo assim que o combustível seja injetado sob alta pressão no final da fase de compressão. Em regimes de alta carga, a válvula é aberta e o combustível é injetado na fase de admissão, logo, a mistura tem características homogêneas. A Figura 8 mostra o mapa da válvula de controle de fluxo, onde é possível observar a atuação da válvula de controle de fluxo nos regimes de baixa rotação.

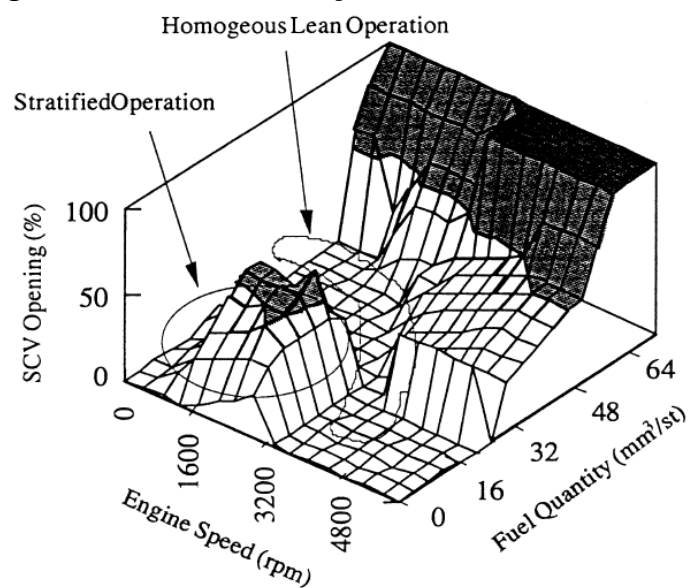

Figura 8 - Mapa da válvula de controle de fluxo do motor D4 [2].

Outras montadoras como a Nissan, Peugeot Citroën e Volkswagen, também contribuíram no desenvolvimento da tecnologia. Entretanto, um marco relevante é a introdução do motor de injeção direta no mercado europeu pela montadora Renault, no ano de 2000. Tendo como base os resultados obtidos pela concorrência, onde os motores de injeção direta não atingiam os resultados teóricos de redução de consumo e apresentavam limitações quanto às emissões de poluentes, principalmente pelo forte foco na operação estratificada, a montadora francesa introduziu o conceito homogêneo de operação, trabalhando apenas na condição estequiométrica. Logo, o principal benefício foi o aumento da taxa de compressão devido a redução de temperatura do combustível na câmara de combustão. A estratégia também foi adotada por outras montadoras, contudo, os resultados e benefícios vislumbrados pela tecnologia não foram atingidos e, em 2006, a DaimlerChrysler lançou no mercado o primeiro motor de injeção direta com processo de combustão guiado por spray e modo estratificado de operação. No motor M272 DE 35, modelo da DaimlerChrysler percursor do processo de combustão guiado por spray, um injetor piezo-elétrico foi posicionado no centro da câmara de combustão e a vela ignição inclinada próxima à válvula de escape. O sistema de injeção desenvolvido pela Bosch injeta combustível a 200 bar de pressão no interior da câmara, logo, quando comparado com os processos de injeção guiado pela parede e guiado pelo ar, desenvolvidos anteriormente, o sistema apresentou consideráveis reduções no consumo de combustível, principalmente devido a operação estratificada em maiores regimes de carga e rotação. Atingindo até $10 \%$ de redução de consumo de combustível no ciclo europeu de condução, a tecnologia se tornou o principal foco de desenvolvimento da indústria e segundo Basshuysen [3] este conceito é o único qual pode extrair todos os benefícios da injeção direta em motores Otto.

\section{MECANISMO DE FORMAÇÃO DO MATERIAL PARTICULADO}

Em linhas gerais, material particulado pode ser caracterizado como sendo todo e qualquer material sólido e líquido presente nos gases de exaustão, à parte da água. É uma complexa mistura de compostos voláteis e não voláteis, aglomerados e adsorvidos numa estrutura de 
núcleo. Sua formação como produto da combustão é um fenômeno físico-químico complexo. Kittelson [6] propõe que a formação de material particulado ocorre em três etapas que se distinguem entre si pelo mecanismo de formação e não pelas características do material formado, sendo elas:

- Etapa de nucleação: com diâmetro médio de 3 a 30 nanometros (nm) é composta predominantemente de compostos orgânicos voláteis e compostos sulfurosos, representando menos de $10 \%$ do total de massa e mais de $90 \%$ do número de particulado emitido;

- Etapa de acumulação: processo onde ocorre a aglomeração e adsorção de materiais na estrutura nuclear, atingindo diâmetro médio de 20 a $500 \mathrm{~nm}$, correspondendo assim a maior parcela de massa de material particulado;

- Etapa grosseira: de 5 a $20 \%$ do total de massa emitida, representa o material acumulado na câmara de combustão e no sistema de exaustão;

A Figura 9 apresenta os mecanismos e suas contribuições em massa e número de material particulado.

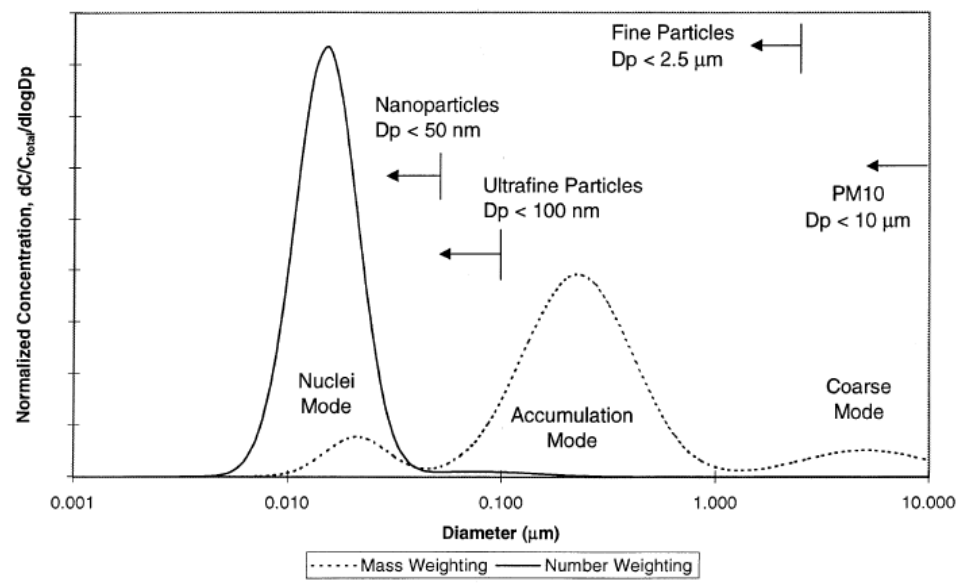

Figura 9 - Distribuição e formação típica do material particulado [6]

Sgro et al. [7] estudaram a origem das partículas dos núcleos em um motor Otto de injeção direta, equipado com injetor de 6 furos à $45^{\circ}$ do eixo do cilindro e pressão de injeção de 150bar. Visando observar principalmente partículas de carbono, o motor foi alimentado com combustível de baixo teor de enxofre e óleo lubrificante com baixo teor de cinzas e enxofre. Utilizando um analisador de mobilidade diferencial (DMA), com ponto de amostragem localizado a 1,6m do coletor de exaustão e sistema de diluição mono-estágio, a distribuição de tamanho das particulas foi determinada. Para levantar a distribuição de carga das partículas, foi utilizada a técnica de espectroscopia de Raman intensificada pela superfície. Diferentes condições de operação do motor foram inicialmente investigadas, tendo como foco a condição de maior produção de partículas dos núcleos. Os autores, concluíram que a condição de marcha lenta produz a menor quantidade de partículas na etapa de acumulação e uma considerável quantidade de partículas na etapa de nucleação. Assim sendo, com o motor operando em tal condição e com uma razão de diluição elevada, visando evitar a condensação dos elementos voláteis, a distribuição modal do diâmetro das partículas é de $2 \mathrm{~nm}$ e a espectroscopia indica que tais partículas são compostas de carbono e são amorfas. Mesmo em diferentes condições de razão de diluição, o número de partículas se mostrou constante, indicando assim ser percurssor do material particulado emitido total. Com razões de diluição menores, pode ocorrer a condensação de compostos orgânicos voláteis, oriundos da queima incompleta do combustível e óleo lubrificante, impactando assim a massa de material 
particulado emitida. Entretanto, segundo Kittelson \& Kraftz [8], a estrutura e composição química dos núcleos ainda não são conclusivas. Isso se deve principalmente ao reduzido diâmetro da estrutura. Sgro et al. sugerem que a origem principal das estruturas dos núcleos seja o processo de combustão, diretamente relacionando com a condição de operação do motor e características físico-químicas do combustível [7]. Todavia, estudos indicam que aditivos metálicos adicionados no óleo lubrificante, como Cálcio (Ca) e Zinco (Zn), podem entrar no sistema de injeção e contribuirem para formação dos núcleos.

Kittelson \& Kraftz relatam que em condições de queima onde a temperatura local excede $1300 \mathrm{~K}$, ocorrem reações de polimerização que resultam em hidrocarbonetos policíclicos aromáticos (HPA). Com seu deslocamento ao longo da chama, inicia o processo de aglomeração de partículas nas estruturas e por consequência dá-se início ao processo de aumento de massa. Uma parcela das partículas supera os limites de frente de chama e oxida, formando dióxido de carbono $\left(\mathrm{CO}_{2}\right)$ e vapor de água. Este processo de oxidação libera energia local, ou seja, é um processo exotérmico que cria regiões de alta temperatura na frente de chama, resultando na formação de óxidos de nitrogênio $\left(\mathrm{NO}_{\mathrm{x}}\right)$. A outra parcela de partículas supera a frente de chama e é emitida pelo sistema de exaustão como material particulado [8].

\section{ESTADO DA ARTE}

A característica dos motores de injeção direta de emitir mais material particulado que os motores de pré-mistura, já é de domínio público. Publicações datadas em 1999 apresentam os resultados iniciais de emissões de material particulado. Maricq et al. [9] utilizando um motor 1,83L de 4 cilindros, com pressão de injeção de 50 bar, avaliaram as emissões em diferentes condições de operação do motor. Com regime de rotação constante a $1500 \mathrm{rpm}$ e diferentes tempos de injeção de combustível, a Figura 10 apresenta os resultados de emissões do motor de injeção direta. A principal característica das emissões de material particulado é a dependência com o modo de operação, ou seja, operando em condição estratificada, a massa total e o número de material particulado são mais de 20 vezes maior que operando em condição homogênea. Os autores também sugerem uma relação entre a emissão de material particulado e regimes de carga e rotação do motor. Em regimes de alta carga e rotação, ocorre um pico de temperatura na combustão, promovendo assim maiores temperaturas nos gases de escapamento. Inicialmente, tal abordagem indica um processo de combustão mais eficiente e com maior oxidação dos núcleos de material particulado, reduzindo assim a emissão final. Entretanto, os resultados apresentam outra tendência, ou seja, de aumento das emissões conforme o aumento dos regimes de carga e rotação do motor. Segundo os autores, uma justificativa plausível é a de que maiores rotações reduzem o tempo de vaporização do combustível, e, maiores regimes de carga requerem uma maior massa de combustível injetado reduzindo a temperatura no interior da câmara, limitando assim a vaporização do combustível. 


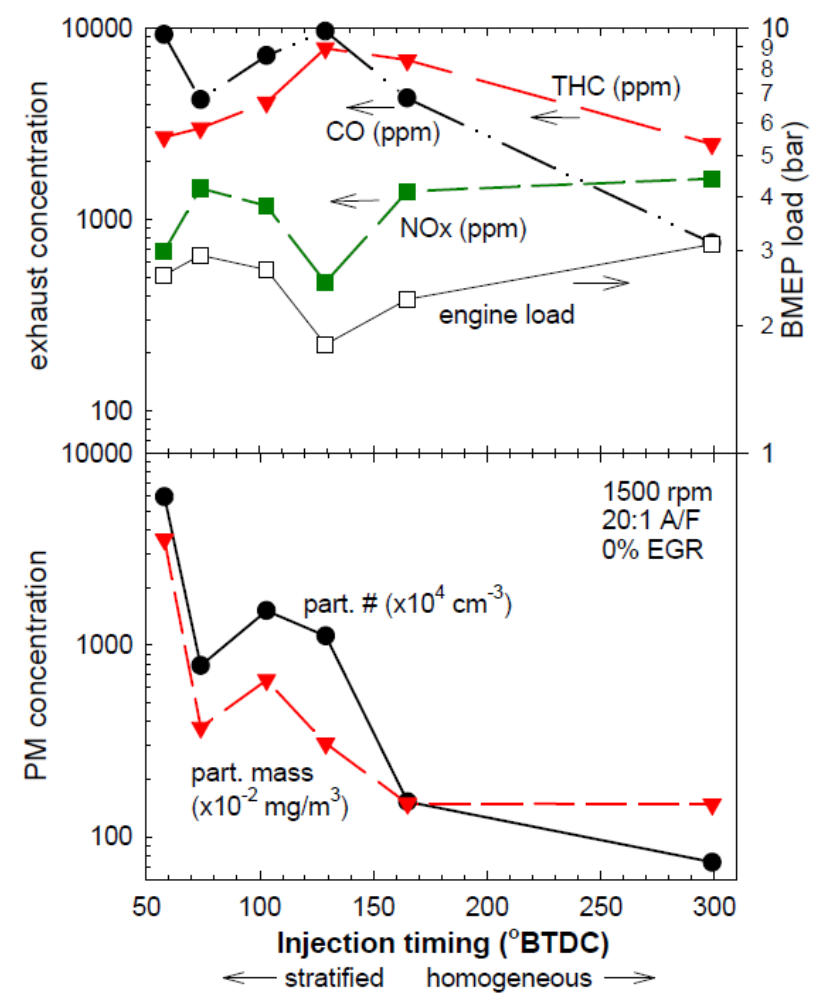

Figura 10 - Emissões em função do tempo de injeção [9]

Em dinamômetro de chassi, Maricq et al. [9] também compararam a massa de material particulado emitido por um veículo de injeção direta com um veículo de pré mistura e um veículo diesel. Conforme apresentado na Figura 11, o motor de injeção direta emitiu aproximadamente 10 vezes mais material particulado que o motor de pré mistura, no ciclo de condução americano FTP-75. Contudo, a emissão de $10 \mathrm{mg} / \mathrm{mi}$ de material particulado do motor de injeção direta estava muito distante do limite norte americano vigente na época para motores diesel, de $80 \mathrm{mg} / \mathrm{mi}$.

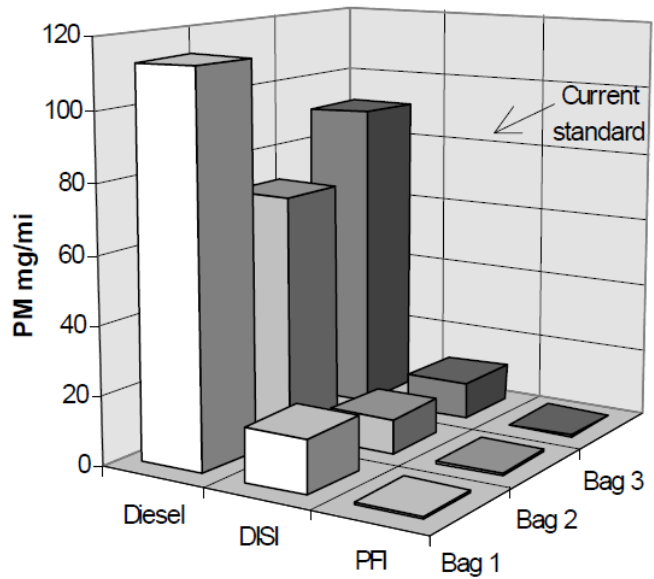

Figura 11 - Comparativo do material particulado emitido no ciclo FTP-75 [9].

Em 2000, Maricq et al. [10] apresentaram a influência da taxa de EGR (exhaust gas recirculation) na distribuição de tamanho do material particulado emitido por um motor de 0,31 L, mono-cilíndrico de injeção direta. Operando em condição ultra-pobre de combustão e regime estacionário, nas diferentes taxas de EGR apresentadas na Figura 12 os tempos de injeção e ignição foram ajustados para se obter o menor consumo de combustível. 


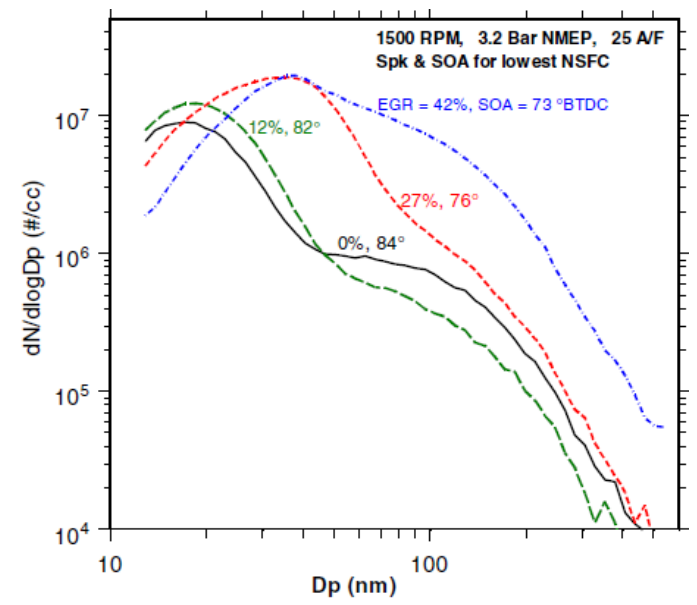

Figura 12 - Emissão de material particulado em função da taxa de EGR [10]

A adoção de sistemas de recirculação em motores de combustão interna visa reduzir a temperatura de combustão e consequentemente a emissão de $\mathrm{NO}_{\mathrm{x}}$. Contudo, tal redução na temperatura diminui a eficiência de oxidação do material particulado, comprometendo assim sua emissão final. Os autores sugerem que a emissão de material particulado em motores de injeção direta seja caracterizada em dois modos distintos, um com partículas de aproximadamente $20 \mathrm{~nm}$ de diâmetro e outro com $100 \mathrm{~nm}$ de diâmetro. Com taxa de $27 \%$ de EGR há uma alteração no modo de distribuição do tamanho das partículas, bem como no número total emitido. No ano de 2000, a tecnologia se mostrava promissora na redução de emissões de material particulado, entretanto, os autores sugerem uma relação entre o design e características do injetor com material particulado emitido.

Com a crescente preocupação da comunidade frente aos níveis de material particulado emitido por motores de injeção direta, Gregory et al. [11] aplicaram a técnica de laser incandescente induzido para medir o material particulado em condições transientes de operação. Conforme apresentado na Figura 13, os autores sugerem uma forte relação entre a emissão de material particulado e condições de aceleração do veículo. Citam também a relação entre a temperatura de operação com a emissão de particulado. Da Figura 13, nos 250 $\mathrm{s}$ iniciais do teste, onde a temperatura do motor e do sistema de pós tratamento não atingiram a condição ótima de operação, a concentração de material particulado é superior à condição de maior temperatura.

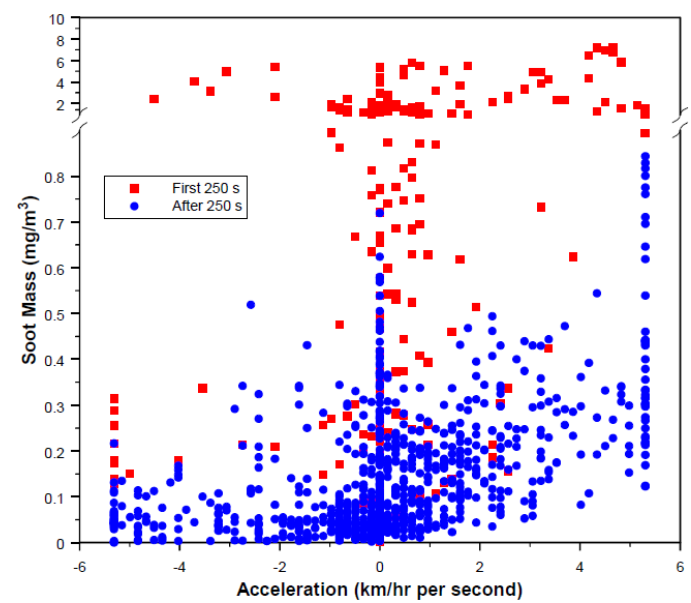

Figura 13 - Emissão de material particulado em acelerações [11]. 
Price et al. [12] avaliaram a emissão de material particulado de motores de injeção direta da primeira e segunda geração, com um motor de pré mistura. Os autores investigaram diferentes condições de contorno, como combustível, relação ar/combustível, tempo de injeção e tempo de ignição. Utilizando a técnica de espectrometria de mobilidade diferencial, com ponto de amostragem à $150 \mathrm{~mm}$ das válvulas de escape dos motores, os autores sugerem que a característica físico-química do combustível utilizado seja o fator de maior influência na formação de material particulado. Os testes foram realizados com tolueno e iso-octano como combustível. Na Figura 14 são apresentadas as curvas de concentração de material particulado em função da relação ar/combustível, do motor de injeção direta da segunda geração, ou seja, com processo de combustão guiado pelo spray, e do de pré mistura. É possível observar que em condições ricas de combustível, suas composição apresentam grande influência na concentração de material particulado. A mesma tendência ocorre em condições pobre de operação, contudo com menor dispersão. Os autores atribuiram tal relação à característica aromática do tolueno, cuja qual é conhecida como percursora da fase de nucleação do material particulado, bem como à relação de carbono e hidrogênio do combustível.

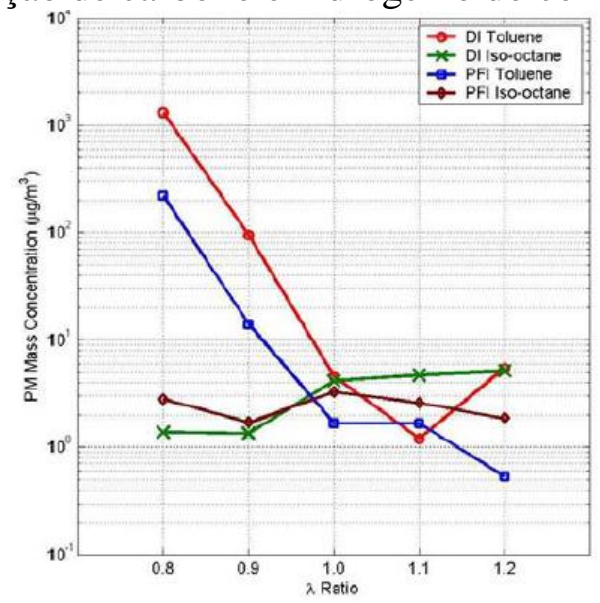

Figura 14 - Influência do combustível na emissão de material particulado [12].

Andersson et al. [13] avaliaram a composição química do material particulado de um motor de injeção direta. A Figura 15 apresenta a estrutura química base do material particulado. Os autores relatam a presença de carbono elementar e derivados do lubrificante no material particulado, sugerindo uma relação entre o nível de carbono com a emissão final de material particulado.

\section{Chemical Analysis of PM Euro 4 VW FSI}

- Elemental Carbon

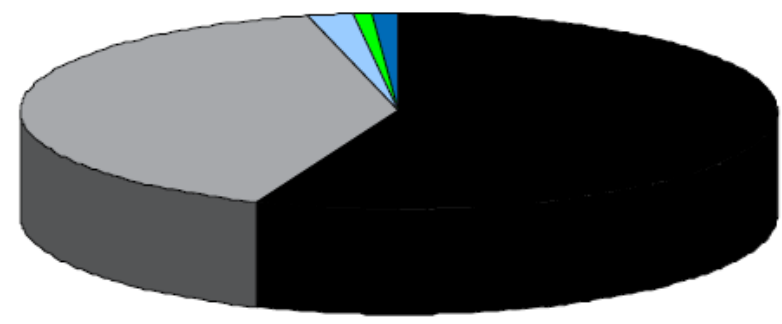

$\square$ Hydrocarbons and Other Volatiles

Anion-bound water

Nitrates

Sulphates

Figura 15 - Análise química do material particulado de um motor de injeção direta. [15]. 
Chen et al. [14], também utilizando a técnica de espectrometria de mobilidade diferencial, avaliaram a influência de etanol na emissão de material particulado. Utilizando um veículo de injeção direta da segunda geração, os autores realizaram uma análise comparativa das emissões de material particulado entre um combustível padrão para ensaios e uma mistura com $10 \%$ de etanol, sob diferentes condições de tempo de injeção e ignição. Os autores sugerem que em condição estratificada de operação, os átomos de oxigênio presentes no etanol reduzem as emissões de material particulado. Entretanto, na operação homogênea, o combustível com $10 \%$ de etanol emitiu até 3 vezes mais material particulado que o combustível de referência. Além da diferença de entalpia de vaporização, o combustível com etanol requer um maior volume para atingir a condição estequiométrica, logo, os autores atribuem tais fatores à maior emissão de material particulado.

Dando continuidade na investigação da influência do etanol nas emissões de material particulado, Chen et al. [15] avaliaram a formação de material particulado em motores de injeção direta quando abastecidos com diferentes misturas de gasolina e etanol. Conforme apresentado na Figura 16, os autores sugerem que a adição de etanol no combustível, quando o motor opera em condição homogênea, resulta numa maior emissão de material particulado. Entretanto, a literatura mais recente apresenta a complexidade do processo de formação de material particulado em motores de injeção direta, se tornando assim inconclusiva.
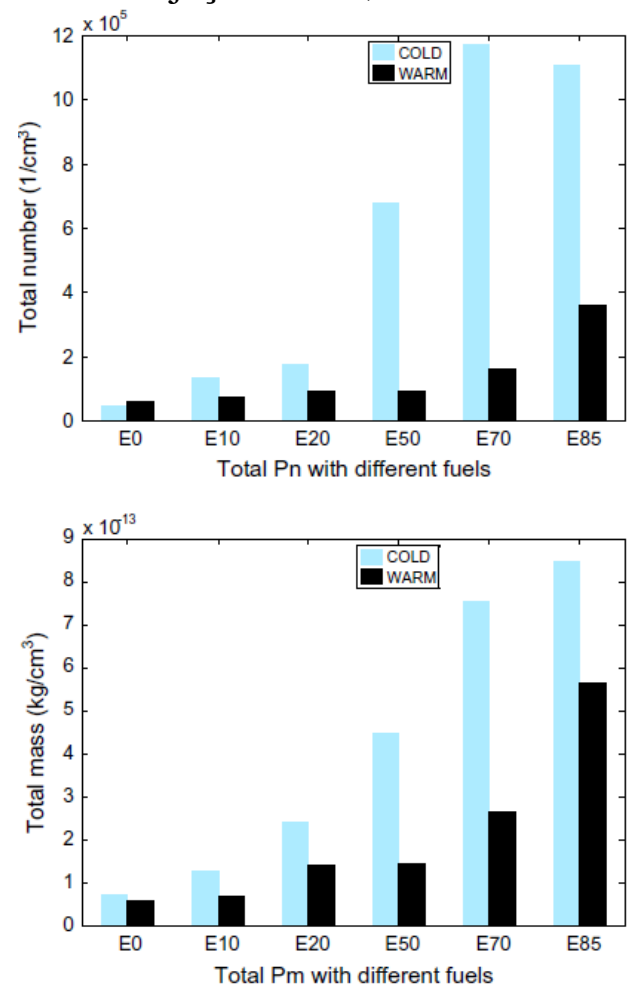

Figura 16 - Emissões de material particulado para diferentes concentrações de etanol [15].

Stein et al. [16] apresentam outro cenário da influência de etanol nas emissões de material particulado. Citam estudos onde a adição de etanol reduziu a emissão de material particulado, e, atribuem tal tendência principalmente à menor temperatura de evaporação do etanol, à ausência de ligações duplas e anéis aromáticos, bem como à presença de átomos de oxigênio no combustível. Sugerem ainda, que estudos que apresentam um aumento nas emissões de material particulado em função da adição de etanol, são resultados da combustão não otimizada para adição de etanol no combustível. 
Em linha geral, Kittelson \& Kraftz concluem que dois mecanismos percursores da formação de material particulado em motores Otto de injeção direta foram identificados. O primeiro está relacionado à condição de operação estratificada, ou seja, quando a injeção de combustível ocorre na fase de compressão. Devido o curto espaço de tempo entre a injeção e a centelha, a vaporização do combustível não é completa, logo a mistura ar/combustível apresenta características heterogêneas, ou seja, com regiões ricas em combustível e com grande potencial para formação de material particulado. $O$ segundo está principalmente relacionado à condição homogênea, ou seja, quando o combustível é injetado ainda na fase de admissão, criando assim acúmulos de combustível nas paredes do cilindro, uma fonte em potencial para formação de material particulado [8].

\section{LEGISLAÇÃ̃}

Até a década de 90, a tecnologia de injeção direta foi alvo de desenvolvimento focado na eficiência energética. Contudo, seus pontos negativos foram introduzidos na comunidade por meio de publicações técnicas e através do programa de medição de material particulado da União Européia. Nos relatórios preliminares do programa europeu já havia indícios da necessidade de regulamentaçãodo material particulado de motores de injeção direta e em 2007, no relatório final da correlação interlaboratorial, foi apresentada a Figura 17. É possível notar que veículos equipados com motores de injeção direta emitem até 10 vezes mais material particulado que veículos com motores Diesel e sistema de pós tratamento com filtro de particulado.

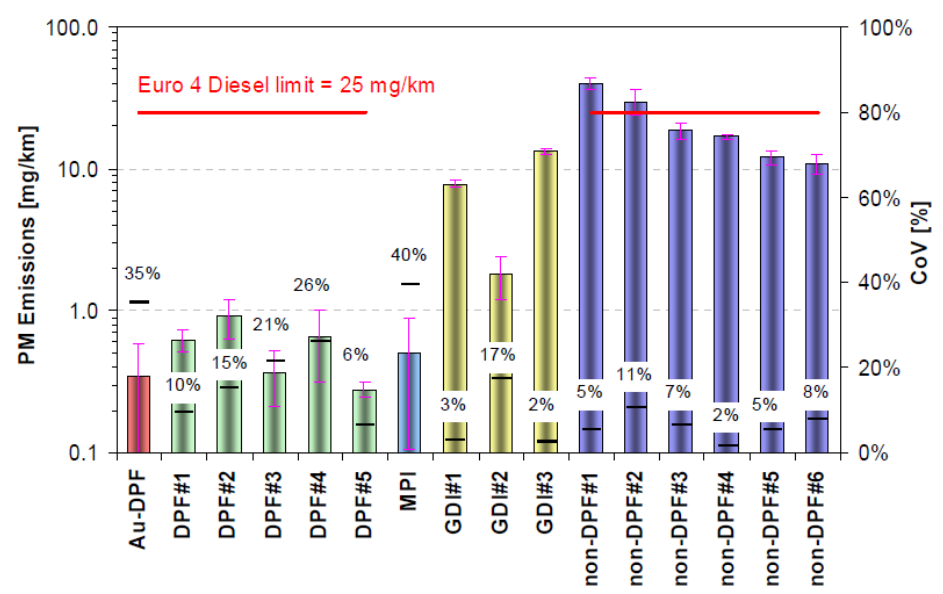

Figura 17 - Distribuição da emissão de material particulado para diferentes veículos [17].

Ainda em 2007, quando da revisão da normativa européia de emissões, estabelecendo os limites para as fases Euro5 e Euro6, e de forma pioneira no cenário global, o material particulado iniciou a ser regulamentado também para motores Otto de injeção direta, conforme Figura 18. 


\begin{tabular}{|c|c|c|c|c|c|c|c|c|c|c|c|c|c|c|c|c|}
\hline \multirow[b]{4}{*}{ Category } & \multirow[b]{4}{*}{ Class } & \multirow{4}{*}{$\begin{array}{c}\text { Reference mass } \\
(\mathrm{RM}) \\
(\mathrm{kg})\end{array}$} & \multicolumn{14}{|c|}{ Limit values } \\
\hline & & & \multirow{2}{*}{\multicolumn{2}{|c|}{$\begin{array}{c}\begin{array}{c}\text { Mass of carbon } \\
\text { monoxide } \\
\text { (CO) }\end{array} \\
\begin{array}{c}\mathrm{L}_{1} \\
(\mathrm{~m} / \mathrm{km})\end{array}\end{array}$}} & \multirow{2}{*}{\multicolumn{2}{|c|}{$\begin{array}{c}\begin{array}{c}\text { Mass of total } \\
\text { hydrocarbons } \\
\text { (THC) }\end{array} \\
\begin{array}{c}\mathrm{L}_{2} \\
(\mathrm{mg} / \mathrm{km})\end{array}\end{array}$}} & \multirow{2}{*}{\multicolumn{2}{|c|}{$\begin{array}{c}\begin{array}{c}\text { Mass of non-methane } \\
\text { hydrocarbons } \\
\text { (NMHC) }\end{array} \\
\begin{array}{c}\mathrm{L}_{3} \\
(\mathrm{mg} / \mathrm{km})\end{array}\end{array}$}} & \multirow{2}{*}{\multicolumn{2}{|c|}{$\begin{array}{c}\begin{array}{c}\text { Mass of oxides } \\
\text { of nitrogen } \\
\left(\mathrm{NO}_{\mathrm{x}}\right)\end{array} \\
\begin{array}{c}\mathrm{L}_{4} \\
(\mathrm{mg} / \mathrm{km})\end{array}\end{array}$}} & \multirow{2}{*}{\multicolumn{2}{|c|}{$\begin{array}{c}\begin{array}{c}\text { Combined mass of total } \\
\text { hydrocarbons and } \\
\text { oxides of nitrogen } \\
\left.\text { (THC }+\mathrm{NO}_{x}\right)\end{array} \\
\begin{array}{c}\mathrm{L}_{2}+\mathrm{L}_{4} \\
(\mathrm{mg} / \mathrm{km})\end{array} \\
\end{array}$}} & \multirow{2}{*}{\multicolumn{2}{|c|}{$\begin{array}{c}\begin{array}{c}\text { Mass of particulate } \\
\text { matter } \\
(\mathrm{PM})\end{array} \\
\begin{array}{c}\mathrm{L}_{5} \\
(\mathrm{mg} / \mathrm{km})\end{array}\end{array}$}} & \multicolumn{2}{|c|}{$\begin{array}{c}\text { Number of particles (1) } \\
(\mathrm{P})\end{array}$} \\
\hline & & & & & & & & & & & & & & & & \\
\hline & & & PI & $\mathrm{CI}$ & $\mathrm{Pl}$ & $\mathrm{CI}$ & PI & $\mathrm{Cl}$ & PI & $\mathrm{Cl}$ & PI & $\mathrm{CI}$ & PI ( $\left.{ }^{2}\right)$ & $\mathrm{CI}$ & PI & $\mathrm{CI}$ \\
\hline M & - & All & 1000 & 500 & 100 & - & 68 & - & 60 & 180 & - & 230 & 5,0 & 5,0 & & \\
\hline \multirow[t]{3}{*}{$\mathrm{N}_{1}$} & $\mathrm{I}$ & $\mathrm{RM} \leq 1305$ & 1000 & 500 & 100 & - & 68 & - & 60 & 180 & - & 230 & 5,0 & 5,0 & & \\
\hline & II & $\begin{array}{c}1305<\mathrm{RM} \\
\leq 1760\end{array}$ & 1810 & 630 & 130 & - & 90 & - & 75 & 235 & - & 295 & 5,0 & 5,0 & & \\
\hline & III & $1760<\mathrm{RM}$ & 2270 & 740 & 160 & - & 108 & - & 82 & 280 & - & 350 & 5,0 & 5,0 & & \\
\hline $\mathrm{N}_{2}$ & & & 2270 & 740 & 160 & - & 108 & - & 82 & 280 & - & 350 & 5,0 & 5,0 & & \\
\hline
\end{tabular}

Figura 18 - Limites de emissões da fase Euro 5 [18].

Com a evolução das pesquisas no segmento e produções científicas de grande notoriedade, a massa total de material particulado assumiu um papel coadjuvante nas legislações, sendo que o foco principal da atenção voltou-se para o número de partículas emitidas. Em 2012, com a publicação da Regulação 459/2012 [19], que revisou os limites de emissões previamente estabelecidos para a fase Euro6, a União Européia passou a regulamentar o número total de partículas de motores de injeção direta, conforme mostrado na Figura 19.

\begin{tabular}{|c|c|c|c|c|c|c|c|c|c|c|c|c|c|c|c|c|}
\hline & & \multirow{4}{*}{$\begin{array}{l}\text { Reference mass } \\
(\mathrm{RM}) \\
(\mathrm{kg})\end{array}$} & \multicolumn{14}{|c|}{ Limit values } \\
\hline & & & \multirow{2}{*}{\multicolumn{2}{|c|}{$\begin{array}{c}\begin{array}{c}\text { Mass of carbon } \\
\text { monoxide } \\
\text { (CO) }\end{array} \\
\begin{array}{c}\mathrm{L}_{1} \\
(\mathrm{mg} / \mathrm{km})\end{array}\end{array}$}} & \multirow{2}{*}{\multicolumn{2}{|c|}{$\begin{array}{c}\begin{array}{c}\text { Mass of total } \\
\text { hydrocarbons } \\
\text { (THC) }\end{array} \\
\begin{array}{c}\mathrm{L}_{2} \\
\text { (mg//km) }\end{array}\end{array}$}} & \multirow{2}{*}{\multicolumn{2}{|c|}{\begin{tabular}{|c|}
$\begin{array}{c}\text { Mass of non-methane } \\
\text { hydrocarbons } \\
\text { (NMHC) }\end{array}$ \\
$\begin{array}{c}\mathrm{L}_{3} \\
(\mathrm{mg} / \mathrm{km})\end{array}$ \\
\end{tabular}}} & \multirow{2}{*}{\multicolumn{2}{|c|}{$\begin{array}{c}\begin{array}{c}\text { Mass of oxides of } \\
\text { nitrogen } \\
\left(\mathrm{NO}_{x}\right)\end{array} \\
\begin{array}{c}\mathrm{L}_{4} \\
(\mathrm{mg} / \mathrm{km})\end{array}\end{array}$}} & \multirow{2}{*}{\multicolumn{2}{|c|}{$\begin{array}{c}\begin{array}{c}\text { Combined mass of } \\
\text { hydrocarbons and } \\
\text { oxides of nitrogen } \\
\left.\text { (THC }+\mathrm{NO}_{x}\right)\end{array} \\
\begin{array}{c}\mathrm{L}_{2}+\mathrm{L}_{4} \\
(\mathrm{mg} / \mathrm{km})\end{array}\end{array}$}} & \multirow{2}{*}{\multicolumn{2}{|c|}{$\begin{array}{c}\begin{array}{c}\text { Mass of particulate } \\
\text { matter } \\
(\mathrm{PM})\left({ }^{1}\right)\end{array} \\
\begin{array}{c}\mathrm{L}_{5} \\
(\mathrm{mg} / \mathrm{km})\end{array}\end{array}$}} & \multicolumn{2}{|c|}{$\begin{array}{l}\text { Number of particles } \\
\text { (PN) }\end{array}$} \\
\hline & & & & & & & & & & & & & & & & \\
\hline Category & Class & & PI & $\mathrm{CI}$ & PI & $\mathrm{Cl}$ & PI & $\mathrm{Cl}$ & PI & $\mathrm{Cl}$ & PI & $\mathrm{Cl}$ & PI (2) & $\mathrm{Cl}$ & $\mathrm{PI}\left(\mathrm{l}^{2}\left(\mathrm{3}^{3}\right)\right.$ & $\mathrm{CI}$ \\
\hline M & - & All & 1000 & 500 & 100 & - & 68 & - & 60 & 80 & - & 170 & 4,5 & 4,5 & $6,0 \times 10^{11}$ & $6,0 \times 10^{11}$ \\
\hline \multirow[t]{3}{*}{$\mathrm{N}_{1}$} & I & $\mathrm{RM} \leq 1305$ & 1000 & 500 & 100 & - & 68 & - & 60 & 80 & - & 170 & 4,5 & 4,5 & $6,0 \times 10^{11}$ & $6,0 \times 10^{11}$ \\
\hline & II & $1305<\mathrm{RM} \leq 1760$ & 1810 & 630 & 130 & - & 90 & - & 75 & 105 & - & 195 & 4,5 & 4,5 & $6,0 \times 10^{11}$ & $6,0 \times 10^{11}$ \\
\hline & III & $1760<\mathrm{RM}$ & 2270 & 740 & 160 & - & 108 & - & 82 & 125 & - & 215 & 4,5 & 4,5 & $6,0 \times 10^{11}$ & $6,0 \times 10^{11}$ \\
\hline $\mathrm{N}_{2}$ & - & All & 2270 & 740 & 160 & - & 108 & - & 82 & 125 & - & 215 & 4,5 & 4,5 & $6,0 \times 10^{11}$ & $6,0 \times 10^{11}$ \\
\hline
\end{tabular}

Figura 19 - Limites de emissões da fase Euro 6 [19].

Nos Estados Unidos da América, a regulamentação do material particulado em motores de injeção direta foi sancionada através da fase CARB LEV III, publicada em Março de 2012. Com data de introdução em 2015, o programa é ousado quanto à redução em masa das emissões ao longo dos anos. Para veículos leves, o limite da primeira etapa é de $10 \mathrm{mg} / \mathrm{mi}$, contudo, no período compreendido entre 2017 e 2021, os veículos devem atingir $3 \mathrm{mg} / \mathrm{mi}$ de material particulado e entre 2025 à 2028, apenas $1 \mathrm{mg} / \mathrm{mi}$. Até o presente momento, o governo norte americano não estabeleceu os limites para o número total de partículas emitidas [20].

\section{CENÁRIO NORTE AMERICANO E EUROPEU DA INJEÇÃO DIRETA}

O desenvolvimento da tecnologia nos diferentes continentes foi segregado devido a diferentes requisitos de emissões e objetivos de consumo de combustível. No princípio de introdução da tecnologia ao consumidor final, campanhas publicitárias das grandes montadores 
apresentavam valores de redução de consumo super-estimados, chegando até a 25\%. Contudo, os valores reais obtidos em campo estavam muito aquém do declarado, criando assim uma imagem negativa do conceito. Outro ponto negativo foi o alto valor agregado, principalmente pelo elevado custo de manufatura e dos sistemas de pós-tratamento [2].

Na Europa, o marco principal para a mudança da imagem, foi a introdução dos motores sobrealimentados. Com a revisão dos valores publicados de redução de consumo para até $15 \%$, a boa impressão de dirigibilidade dos veículos, devido ao platô de torque disponível numa maior faixa de rotação do motor, criou uma boa percepção da tecnologia, mostrando-se assim competitívo com os veículos Diesel [2]. Em 2003 a injeção direta representava 1\% do mercado europeu de veículos leves e em 2012 deteve 25\% da participação do mercado [21].

Nos Estados Unidos da América, a tecnologia foi introduzida em larga escala em 2007 e em 2008 representava $3,1 \%$ do mercado. Com o amadurecimento da tecnologia e fortes apelos pela redução de emissão de $\mathrm{CO}_{2}$, em 2013 a injeção direta representou 30,8\% do mercado total de veículos, conforme Figura 20. Considerando somente o mercado de carros leves, a injeção direta representou 37,8\% do mercado, no ano de 2013 [22].

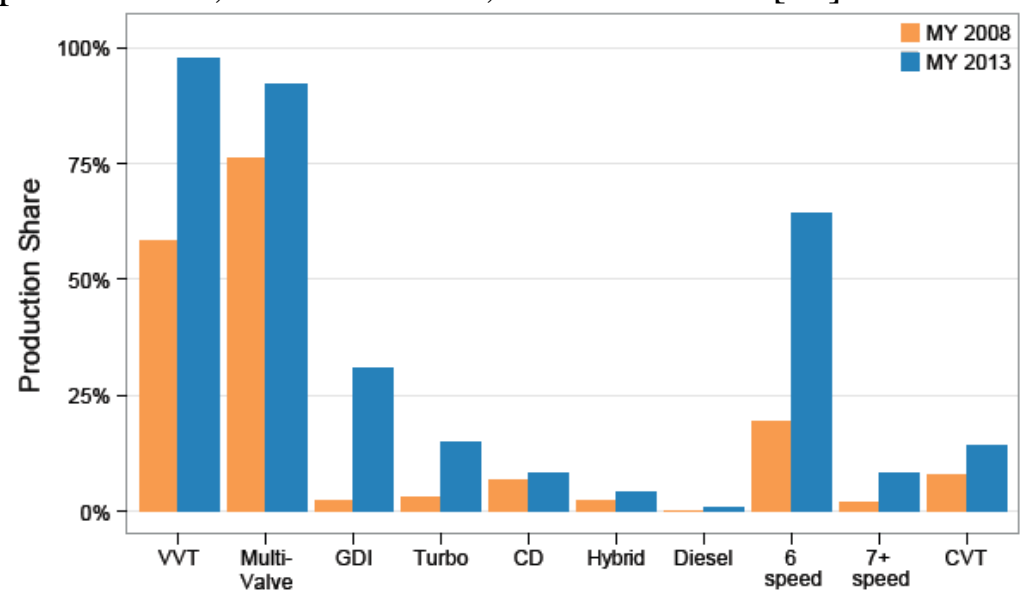

Figura 20 - Participação de mercado das diferentes tecnologias no mercado norte americano [22].

\section{CONCLUSÃO}

A injeção direta em motores Otto é similar ao processo atual de injeção dos motores Diesel. Sua principal característica é injetar combustível sob alta pressão no interior da câmara de combustão, seja na fase de admissão ou na fase de compressão. Além de poder trabalhar em condições ultra pobre de concentração de combustível, a injeção no interior da câmara permite maiores taxas de compressão do motor, uma vez que a temperatura da mistura ar/combustível é reduzida. Tal condição faz com que os motores equipados com injeção direta sejam mais eficientes, emitam menos $\mathrm{CO}_{2}$ e reduzam o consumo de combustível, quando comparados aos motores de pré mistura.

A tecnologia de injeção direta em motores Otto foi inicialmente desenvolvida pela indústria aeronáutica na primeira guerra mundial. Sua primeira aplicação em veículos automotores ocorreu na década de 50, pela Daimler-Benz, obtendo resultados significativos em desempenho e redução de consumo de combustível. Devido às condições econômicas e 
incentivos do governo da época, o desenvolvimento da tecnologia não obteve grandes avanços por aproximadamente duas década, e, somente nos anos 80, com fortes apelos na redução de emissões e eficiência dos motores, a injeção direta se tornou objeto de pesquisa e desenvolvimento das grandes montadoras. No início de sua aplicação em larga escala no setor automotivo, a tecnologia de injeção direta sofreu alguns entraves, principalmente devido aos custos atrelados, contudo, diferentes montadoras atuaram e contribuíram no desenvolvimento e aplicação da tecnologia.

O primeiro processo de combustão de injeção direta adotado na indústria automotiva, o denominado guiado pela parede, se baseia nas características geométricas do pistão para criar uma mistura ar/combustível inflamável na região próxima à vela de ignição. Tal conceito foi de extrema importância no desenvolvimento da tecnologia, uma vez que proporcionou uma percepção positiva por parte dos consumidores finais. Todavia, com a evolução dos programas globais de redução de emissões de poluentes de veículos automotores, o principal fator negativo da tecnologia, a elevada emissão de material particulado, se tornou ítem de destaque na comunidade internacional. A literatura atribui o acúmulo de combustível líquido nas paredes da câmara de combustão, como fator predominante à elevada emissão de material particulado do processo de combustão guiado pela parede.

No decorrer dos anos, outros dois processos de combustão foram desenvolvidos, contudo o principal destaque se dá ao processo guiado por spray. Neste processo, o perfil do spray de combustível injetado é o fator principal da combustão. Sua principal característica é poder trabalhar em condições estratificadas e ultra pobre. Contudo, em condição estratificada de operação, estudos apresentam uma grande concentração de material particulado, e, atribuem este fator ao reduzido tempo de vaporização do combustível e de formação da mistura ar/combustível.

A influência do etanol no processo de combustão dos motores de injeção direta é um tema a ser melhor explorado. A mais recente literatura internacional não é conclusiva, uma vez que diferentes publicações sugerem diferentes tendências de formação de material particulado.

Nas últimas revisões dos limites de emissões de veículos automotores da União Europeia, a massa de material particulado passou a ser regulamentada para motores Otto de injeção direta. $\mathrm{Na}$ mais recente revisão, onde os limites da fase Euro6 foram determinados, o número total de partículas também foi introduzida como ítem a ser controlado. Nos Estados Unidos da América, há regulamentação apenas para a massa total de material particulado emitido por motores de injeção direta.

\section{REFERÊNCIAS}

[1] European Commission. The Auto-Oil II Programme. Disponível em http://ec.europa.eu/environment/archives/autooil/pdf/auto-oil_en.pdf. Acesso em: 14/05/2014. [2] ZHAO, F.; LAI, M.-C.; HARRINGTON, D.L. Automotive spark-ignited direct-injection gasoline engines. Progress in Energy and Combustion Science, 25, 437-562, 1999.

[3] BASSHUYSEN, Richard van. Gasoline Engine with Direct Injection. Germany: Vieweg+Teubner, 2009. 
[4] ALKIDAS, Alex; EL TAHRY, Sherif. Contributors to the Fuel Economy Advantage of DISI Engines Over PFI Engines. SAE Technical Paper, 2003-01-3101, 2003.

[5] IWAMOTO, Y.; NOMA, K.; YAMAUCHI, T.; ANDO, H. Development of gasoline direct injection engine. SAE Technical Paper, 970541, 1997.

[6] KITTELSON, David. Engines and Nanoparticles: A Review. J. Aerosol Sci., 29, 575-588, 1998.

[7] SGRO, Lee Anne; SEMENTA, Paolo; VAGLIECO, Bianca Maria; RUSCIANO, Giulia;

D'ANNA, Andrea. Investigating the origin of nuclei particles in GDI engine exhausts.

Combustion and Flame, 159, 1687-1692, 2012.

[8] KITTELSON, David; KRAFT, Markus. Particle Formation and Models in Internal

Combustion Engines. United Kingdom: University of Cambridge, 2014.

[9] MARICQ, M. Matti; PODSIADLIK, Diane H.; BREHOB, Diana D.; HAGHGOOIE, Mohammad. Particulate Emissions from a Direct-Injection Spark-Ignition (DISI) Engine.

SAE Technical Paper, 1999-01-1530, 1999.

[10] MARICQ, M. Matti; MUNOZ, Ruben H.; YANG, Jialin; ANDERSON, Richard W.

Sooting Tendencies in an Air-Forced Direct Injection Spark-Ignition (DISI) Engine. SAE

Technical Paper, 2000-01-0255, 2000.

[11] SMALLWOOD, Gregory J.; SNELLING, David R.; GÜLDER, Ömar L; CLAVEL, Dan; GAREAU, Daniel; SAWCHUK, Robert. Transient Particulate Matter Measurements from the Exhaust of a Direct Injection Spark Ignition Automobile. SAE Technical Paper, 2001-01-3581, 2001.

[12] PRICE, Philip; STONE, Richard; COLLIER, Tony; DAVIES, Marcus. Particulate Matter and Hydrocarbon Emissions Measurements: Comparing First and Second Generation DISI with PFI in Single Cylinder Optical Engines. SAE Technical Paper, 2006-01-1263, 2006.

[13] ANDERSSON, Jon; KEENAN, Matthew; AKERMAN, Karin. GDI Particles Legislation, Current Levels and Control. Disponível em:

http://www.cambridgeparticlemeeting.org/sites/default/files/Presentations/2009/JAndersson(R icardo)_2009_GDI_PM.pdf. Acesso em: 03/04/2014.

[14] CHEN, Longfei; BRAISHER, Mike; CROSSLEY, Alison; STONE, Richard. The Influence of Ethanol Blends on Particulate Matter Emissions from Gasoline Direct Injection Engines. SAE Technical Paper, 2010-01-0793, 2010.

[15] CHEN, Longfei; STONE, Richard; RICHARDSON, Dave; A study of mixture preparation and PM emissions using a direct injection engine fuelled with stoichiometric gasoline/ethanol blends. Fuel, 96, 120-130, 2010.

[16] STEIN, Robert; ANDERSON, James; WALLINGTON, Timothy. An Overview of the Effects of Ethanol-Gasoline Blends on SI Engine Performance, Fuel Efficiency, and Emissions. SAE Technical Paper, 2013-01-1635, 2013.

[17] ANDERSSON, Jon; GIECHASKIEL, Barouch; MUÑOZ-BUENO, Rafael;

SANDBACH, Emma; DILARA, Panagiota. Particle Measurement Programme (PMP) Lightduty Inter-laboratory Correlation Exercise (ILCE_LD) Final Report. Disponível em:

http://ies.jrc.ec.europa.eu/uploads/fileadmin/Documentation/Reports/Emissions_and_Health/ EUR_2006-2007/EUR_22775_EN.pdf. Acesso em: 11/05/2014.

[18] EUROPEAN UNION. Regulation (Ec) No 715/2007 of The European Parliament And Of The Council of 20 June 2007. Publicado no Official Journal of the European Union, L171.

[19] EUROPEAN UNION. Commission Regulation (EU) No 459/2012 of 29 May 2012.

Publicado no Official Journal of the European Union, L142. 
[20] HENRY, Cary. Meeting Future Global Particulate Emission Standards. Disponível em: http://www.crcao.org/workshops/2014AFEE/Final\%20Presentations/Day\%201\%20Session\% 202\%20SI-Systems\%20Presentations/2-

4\%20Henry,\%20Cary\%20_SwRI_Meeting\%20Future\%20Global\%20Particulate\%20Emissio n\%20Standards\%20v4.pdf. Acesso em 15/05/2014.

[21] THE INTERNATIONAL COUNCIL ON CLEAN TRANSPORTATION. European Vehicle Market Statistics - Pocketbook 2013. Disponível em

http://www.theicct.org/sites/default/files/publications/EU_vehiclemarket_pocketbook_2013 Web.pdf. Acesso em: 13/05/2014.

[21] UNITED STATES ENVIRONMENTAL PROTECTION AGENCY. Light-Duty Automotive Technology Carbon Dioxide Emission, and Fuel Economy Trends: 1975 Through 2013. Disponível em http://www.epa.gov/fueleconomy/fetrends/1975-2013/420r13011.pdf. Acesso em:11/05/2014. 